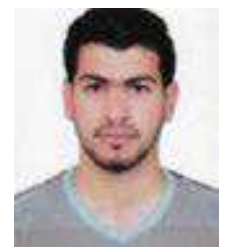

Mohammed Abed

Self-compacting high-performance concrete (SCHPC) is a special type of concrete, which could perform optimally with respect to flow characteristics, strength, transport properties and durability while maintaining the required service life under a given set of material load exposure conditions. Therefore, the production of SCHPC involves more stringent control on the selection of constituent materials than do other types of concrete. Optimal mix design of SCHPC is assessed to optimise fresh and hardened properties. The optimisation has been based on the basic material aspects of SCHPC, namely, aggregate fraction distribution, water to cement $(w / c)$ ratio, and cement content, in addition to the mixing procedure. Thus, all the proposed factors have to be considered to achieve the maximum possible compressive strength by taking into considerations the minimum required highrange water reducer admixture (HRWRA) dosage. SCHPC proved its sensitivity to the ingredient proportions and mixing procedure, which is much more than other types of concrete, where they had a significant effect on the compressive strength and workability performance of SCHPC.

Keywords: self-compacting concrete, high-performance concrete, compressive strength, mixing proportions, mixing procedure

\section{SELF-COMPACTING CONCRETE}

Self-compacting concrete (SCC) is a special type of concrete which spreads through congested reinforcement, reaches every corner of frameworks and consolidates under its own weight, thus providing excellent filling capability and good segregation resistance (Khayat, 1999). Such difficulties, such as lack of skilled workers and durability damages caused by inadequate compaction, complex and difficult shapes of structural elements and congestion of steel reinforcement, were the main motivations for Japanese researchers to introduce SCC, which offers health and safety benefits (Okamura and Ouchi, 2003). However, normal SCC remains prone to poor durability and strength, which could be overcome by the use of cement replacing materials (CRMs) and reduction of the water to binder $(\mathrm{w} / \mathrm{b})$ ratio.

\section{HIGH-PERFORMANCE CONCRETE}

High-performance concrete (HPC) was introduced by researchers as a result of their trials for overcoming the drawbacks of conventional normal concrete. They changed the concrete constituents, mixing procedure and carrying process to improve the particular zone of hydrated paste in the proximity of aggregates, which is called the interfacial transition zone (ITZ). The American Concrete Institute (ACI) defines $\mathrm{HPC}$ as 'a concrete meeting special combinations of perfor- mance and uniformity requirements that cannot always be achieved routinely using conventional constituents and normal mixing' (ACI CT-13, 2013). The major disadvantage of HPC is its low flow and filling capability caused by the low $\mathrm{w} / \mathrm{b}$ ratio, which could overcome by the use of High-range water reducer admixture (HRWRA) and CRMs.

An alternative in the advancement of concrete technology is the combination of the performance characteristics high strength and durability of HPC with the workability characteristics high flow and filling capability of SCC to produce Self-compacting high-performance concrete (SCHPC).

\section{SELF-COMPACTING HIGH- PERFORMANCE CONCRETE}

SCHPC is a special type of concrete, which could perform optimally with respect to flow characteristics, strength, transport properties and durability while maintaining the required service life under a given set of material load exposure conditions. SCHPC's performance at fresh and hardened states differentiate it from ordinary concrete types. This feature is driven by the incorporation of special ingredients in certain proportions, such as HRWRA and CRMs, in addition to standard materials used for all concretes, such as aggregates, sand, cement and water (Safiuddin, 2008).

The proportions of SCHPC mixtures also differ from those used in ordinary concrete; binder volume, fine aggregate and powders and HRWRA are higher in the former than in the 


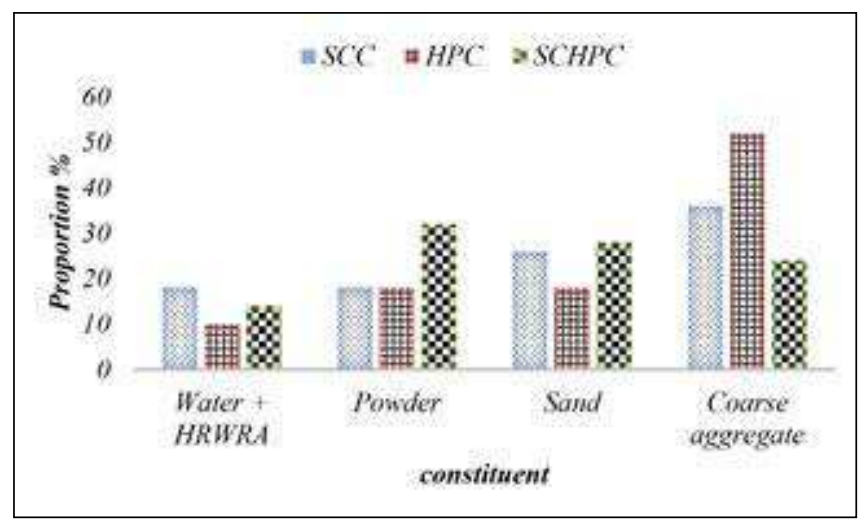

Fig. 1: Typical constituents' ratios of SCC, HPC and SCHPC

latter, whereas the $\mathrm{w} / \mathrm{b}$ ratio and coarse aggregate are lower. The $\mathrm{w} / \mathrm{b}$ ratio is recommended to be from 0.2 to 0.4 in case of SCHPC (Persson, 2001). Ghanbari (2011) proposed typical ratios of constituents for normal SCC and HPC and for SCHPC, as shown in Fig.1.

\subsection{Advantages of SCHPC}

SCHPC offers more advantages than does ordinary concrete and includes the advantages of SCC and HPC; these advantages could be grouped into three (Cameron, 2003; Okamura and Ouchi, 2003; EFNARC, 2005; EFNARC, 2002; Safiuddin, 2008), which are discussed in the following sub-sections.

\subsubsection{Constructional value}

SCHPC flows through and around reinforcing steel under self-weight without using any means of compaction, thereby enhancing compactness and reducing porosity and consequently providing improved strength. Its own compaction facilitates and simplifies the execution process of complex design elements and cast of complicated architectural forms, especially in case with large amounts of reinforcement in small sections. SCHPC is also a watertight concrete; it reduces transport properties, enhances durability and eliminates surface pores, thus providing good finishing without the need for improvement.

\subsubsection{Environmental value}

The construction environment could be improved with reduction of construction noise and decrease of construction time, where a concrete vibrating equipment is not required. SCHPC consumes large amounts of CRMs (waste materials), which saves the environment from excessive waste materials, cement production and disposal places.

\subsubsection{Economic value}

SCHPC helps in decreasing the number of required labourers for the transport and placement of concrete, thereby reducing the costs of construction and saving large quantities of concrete due to the reduced sections of structural components. This material allows for a quickened reuse of formwork, which can last longer due to the elimination of vibration equipment and thus enhances the production rate.

\subsection{Performance criteria of SCHPC}

The use of HRWRA for producing high levels of workability and segregation-resistant concretes was introduced more than

Table 1: Performance criteria of SCHPC (Safiuddin, 2008)

\begin{tabular}{|c|c|c|}
\hline Methods & Properties & Performance criteria \\
\hline \multicolumn{3}{|c|}{ SCC properties } \\
\hline Slump & Filling ability & $250-280 \mathrm{~mm}$ \\
\hline Slump flow & Filling ability, segregation resistance & $550-850 \mathrm{~mm}$ \\
\hline V-funnel flow & Filling ability, segregation resistance & $5-14 s$ \\
\hline Orimet flow with $80 \mathrm{~mm}$ orifice & Filling ability, segregation resistance & $2.5-9 s$ \\
\hline Filling percentage in fill-box & Filling ability, passing ability & $90 \%-100 \%$ \\
\hline Blocking ratio in L-box & Filling ability, passing ability, segregation resistance & $>0.8$ \\
\hline Filling height in $U$-box & Filling ability, passing ability & $30 \mathrm{~mm}$ \\
\hline Slump cone - J-ring flow & Reduction in slump flow as measure of passing ability & $50 \mathrm{~mm}$ \\
\hline Penetration depth & Segregation resistance & $8 \mathrm{~mm}$ \\
\hline Sieve segregation & Segregation resistance & $18 \%$ \\
\hline \multicolumn{3}{|c|}{ HPC properties } \\
\hline Air content by pressure method & Fresh air content & $4 \%-8 \%$ \\
\hline Axial compression on cylinders & 28- and 91-day compressive strength & $>40 \mathrm{MPa}$ \\
\hline Ultrasonic pulse velocity by PUNDIT & Physical quality or condition (packing, uniformity, etc.) & $\geq 4575 \mathrm{~m} / \mathrm{s}$ \\
\hline Porosity by fluid displacement method & Porosity by fluid displacement method & $7 \%-15 \%$ \\
\hline Absorption by water saturation technique & Water absorption as indicator of durability & $3 \%-6 \%$ \\
\hline True electrical resistivity by Wenner probe & Electrical resistance to corrosion & $>5-10 \mathrm{k} \Omega-\mathrm{cm}$ \\
\hline Rapid chloride ion penetration & Electrical charge passed as indicator of corrosion resistance & $<2000 C$ \\
\hline Normal chloride ion penetration at 6 months & Penetrated chloride value as indicator of corrosion resistance & $<0.07 \%$ \\
\hline Durability factor after 300 cycles of freeze-thaw & Resistance to freezing and thawing & $>0.8$ \\
\hline
\end{tabular}


one decade before the development of SCHPC (The first prototype of SCHPC was developed in 1988.) (Okamura, 1995; Safiuddin, 2008; Collepardi, 1976). The Japanese concrete industry commercialised SCHPC in the forms of 'non-vibrated concrete', 'super-quality concrete', and 'biocrete'.

SCHPC has to fulfil the performance criteria of SCC in the fresh state and of hardened HPC to ensure adequate mechanical and durability properties. Safiuddin (2008) summarised these performance criteria, which could be specified for SCHPC by an examination of several SCC and HPC works (Bui et al., 2002; Khayat, 2000; Kosmatka and Cement Association of, 2002; EFNARC, 2005; EFNARC, 2002). These performance criteria are presented in Table 1 .

\subsection{Material aspects of SCHPC}

Similar to ordinary concrete, SCHPC consists of cement, coarse aggregates, fine aggregates and water; however, HRWRA and CRMs are highly important in SCHPC. The characteristics of its ingredients highly affect its performance in fresh and hardened states. Therefore, the production of SCHPC involves more stringent control on the selection of constituent materials than do other types of concrete. The constituent materials are the defining factors in achieving the expected benefits from SCHPC.

\subsubsection{Coarse aggregate}

Coarse aggregate is that retained in a $4.75 \mathrm{~mm}$ (No. 4) sieve. It is a main ingredient and constituent of concrete and distinguishes concrete from mortar. The physical characteristics, porosity and grading of coarse aggregate significantly influence the performance of SCHPC by affecting its fresh and hardened properties (Okamura, 1995; Xie et al., 2002). The use of small coarse aggregates measuring 20-25 mm at most is preferred in SCHPC for enhanced strength and reduced segregation (Kwan, 2000). Round and angular aggregates are advantageous for SCHPC either in fresh or hardened state; however, round aggregates are better than angular aggregates for improved flowing ability, whereas rough and angular aggregates lead to high strength and strong interfacial bond (Geiker et al., 2002; Taylor et al., 1996). The porosity and reactivity of coarse aggregates play an important role in the durability of SCHPC; porous aggregates negatively affect strength and frost resistance.

The gradation of coarse aggregates is likewise important for the fresh and hardened properties of SCHPC; well-graded coarse aggregates enhance the flowing ability and segregation resistance in fresh concrete (Neville, 2009). It also produces dense particle packing, which improves hardened properties (Tasi et al., 2006).

\subsubsection{Cement replacement materials}

CRMs or supplementary cementing materials are powder materials that contribute to the properties of hardened concrete through hydraulic and/or pozzolanic activity. In case of SCHPC; high strength and good durability are the prime goals. Thus, CRMs are highly important to achieving these objectives and an essential material that must be used for promoting SCHPC. CRMs are considerably helpful in enhancing concrete's properties through their physical and chemical effects on material packing and microstructure (Hassan et al., 2000; Hooton, 2000; Khatri et al., 1995). Such standards specify the physical and chemical requirements for natural and artificial CRMs, which provide the limits for fineness, expansion or contraction, pozzolanic activity, uniformity, reactivity, limits for several chemical components and igneous loss.

\subsubsection{High-range water reducer admixture}

The SCHPC cannot be achieved without the use of HRWRA, which is also known as superplasticiser. It improves the flowing ability and reduces the yield stress and plastic viscosity of concrete by its liquefying action (Yen et al., 1999). HRWRA helps in enhancing the strength and durability of concrete by improving hydration through increased dispersion of cement particles and decreased quantity of mixing water for a given flowing ability (Hover, 1998). HRWRA comes in four types, among which polycarboxylate HRWRA, a second-generation HRWRA, is generally preferred for producing SCHPC. The required amount of HRWRA changes significantly with the concrete's constituents, especially with the substantial difference between the CRMs in their structures and physical properties and with the roughness and absorption of the used aggregate.

\subsection{Sustainable SCHPC}

The construction industry is among the fields most affected by the ongoing sustainability debate primarily due to the substantial environmental impact resulting from the production of building materials, construction of buildings and structures and the subsequent use thereof (Mueller et al., 2017). Concrete can become green or environmental friendly when one or more of the following properties is achieved (Suhendro, 2014).

1. It uses waste materials as at least one of its components.

2. Its production process does not lead to environmental destruction.

3. It enhances the durability of concrete, thereby extending the latter's service life and reducing long-term resource consumption.

4. It exhibits superior performance and life cycle sustainability without destroying natural resources.

For developing clean concrete production technologies that reduce $\mathrm{CO}_{2}$ emission and consumed energy or fuel derived from fossil in the cement manufacturing process, the use of recycled cement/concrete and alternative aggregates is being explored.

Approximately $10 \%$ of the total man-made $\mathrm{CO}_{2}$ emitted into the atmosphere is produced during cement manufacturing (Long et al., 2015). Researchers have attempted to produce sustainable concrete mainly through utilising waste materials (construction or industrial waste) and evaluating the sustainability of these new types of concrete not only by their ecological impact but also by their technical performance, i.e. their mechanical, physical and chemical properties (Mueller et al., 2017). As Ajdukiewicz and Kliszczewicz (2002) stated in their research, green high-performance concrete is the future of concrete development. Thus based on the materials aspects of SCHPC, three possibilities could propose a sustainable SCHPC:

1. Recycled concrete aggregate could be used partially for producing SCHPC, which is a porous crushed aggregate.

2. Unpossessed waste powder materials could be used as CRMs for producing SCHPC without any processing preceding the use or consumption of any energy for this purpose.

3. An optimised minimum dosage of HRWRA could be used for producing SCHPC using waste powder materials and recycled concrete aggregate. 


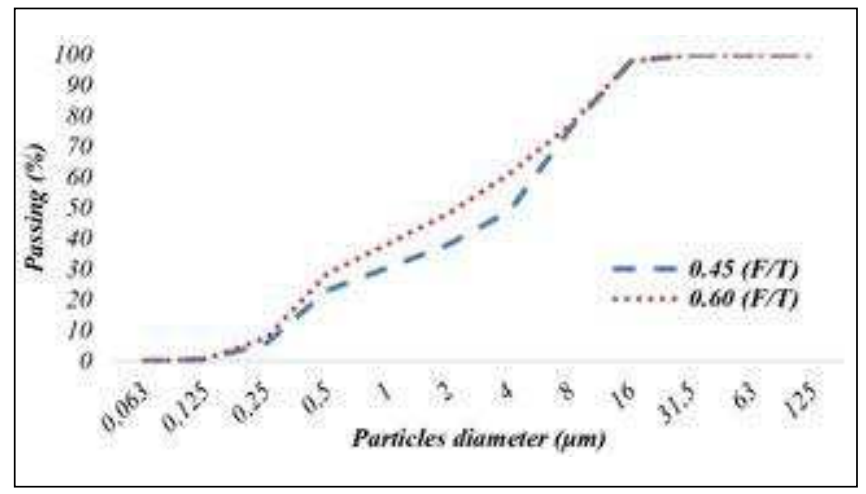

Fig. 2: Grading curves of the aggregate

\section{CASE STUDY: REFERENCE SCHPC MIXTURE OPTIMIZATION}

An initial optimisation exercise was performed for specifying the most appropriate constituent proportions and mixing procedure of the reference mixture of SCHPC. Ahmad and Alghamdi (2014) defined the optimization of the concrete mixture design as 'a process of search for a mixture for which the sum of the costs of the ingredients is lowest, yet satisfying the required performance of concrete, such as workability strength and durability'.

The optimization was based on the targeted compressive strength and workability performance, which were $75 \mathrm{MPa}$ and (SF2 class of slump flow and VF1 viscosity class) respectively. Four variables were optimised, namely, aggregate fraction distribution, water to cement $(\mathrm{w} / \mathrm{c})$ ratio, cement content, and mixing procedure. Two aggregate fraction distributions were optimised. The first one was $45 \%$ for $0 / 4 \mathrm{~mm}$ fraction and $55 \%$ for $4 / 16 \mathrm{~mm}$ fraction, whereas the second was $60 \%$ for $0 / 4$ fraction and $40 \%$ for $4 / 16$ fraction, which of which fit the requirements of BS $E N$ 1260:2002+A1 (2008) and shown in Fig. 2. In addition, two w/c ratios, namely, 0.35 and 0.38, were selected to be tested for their effect on the HRWRA demand and compressive strength. Finally, two amounts of cement content, namely, 450 and $500 \mathrm{~kg} / \mathrm{m}^{3}$, were investigated.

\subsection{Experimental program}

An experimental program was considered in the purpose of studying the effect of the proposed factors and optimizing the reference SCHPC mixture design. Eight concrete mixtures have been produced with taking into consideration two typical levels of each of the three key factors affecting the performance of concrete mixtures, in addition to observe the efficiency of the mixing procedure and the demanded dosage of HRWRA to achieve the intended workability. The combinations of the levels of the three factors for all eight-trial mixtures are shown in Table 2.

Ordinary Portland cement CEM I $42.5 \mathrm{~N}$ in accordance with BS EN 197-1 (2011) has been used, as well as the maximum aggregate size used was $16 \mathrm{~mm}$, which has been chosen based on the literature investigations. The aggregate was a natural river quartz and mainly in two proportions; the fine fraction of aggregate $(0 / 4 \mathrm{~mm})$ and the coarse fraction of aggregate $(4 / 16 \mathrm{~mm})$. The mixing water was tap water that complies with the requirements of $B S E N$ 1008:2002 (2011) while to achieve the rheological properties of the fresh SCHPC; HRWRA has been used. The used HRWRA was Sika ViscoCrete- 5 Neu, which is a modified polycarboxylates aqueous solution.
Table 2: Trail mixtures (key factors)

\begin{tabular}{|c|c|c|c|}
\hline $\begin{array}{c}\text { Mixture } \\
\text { name }\end{array}$ & $\begin{array}{c}\text { Fine to total } \\
\text { aggregate ratio } \\
(\boldsymbol{F} / \boldsymbol{T}) \%\end{array}$ & $\begin{array}{c}\text { Water to cement } \\
\text { ratio }(\boldsymbol{w} / \mathbf{c}) \%\end{array}$ & $\begin{array}{c}\text { Cement con- } \\
\text { tent }(\boldsymbol{C c}) \\
\mathbf{k g} / \boldsymbol{m}^{3}\end{array}$ \\
\hline $\boldsymbol{M 1}$ & 0.45 & 0.35 & 500 \\
\hline $\boldsymbol{M 2}$ & 0.45 & 0.35 & 450 \\
\hline $\boldsymbol{M 3}$ & 0.45 & 0.38 & 450 \\
\hline $\boldsymbol{M 4}$ & 0.45 & 0.38 & 500 \\
\hline $\boldsymbol{M 5}$ & 0.60 & 0.35 & 500 \\
\hline $\boldsymbol{M 6}$ & 0.60 & 0.35 & 450 \\
\hline $\boldsymbol{M} 7$ & 0.60 & 0.38 & 450 \\
\hline $\boldsymbol{M 8}$ & 0.60 & 0.38 & 500 \\
\hline
\end{tabular}

Eight concrete mixtures were produced in consideration of the aforementioned variables. For each; four (150x150x150 $\mathrm{mm}$ ) concrete cubes have been tested for the compressive strength at age of 28 days. The most appropriate mixing procedure was performed for a total mixing time of $4.5 \mathrm{~min}$ partitioned into three stages by using an electric concrete mixer. After each stage, the ingredients were manually mixed for achieving the highest homogeneity. Fig. 3 explains the mixing procedure, which has been proposed based on a number of trials for achieving the minimum HRWRA demand and higher strength. The slump flow and $\mathrm{v}$-funnel tests have been conducted directly after mixing to check if the mix achieved the SF2 slump flow class and VF1 viscosity class based on EFNARC (2005). The SF2 slump flow class is ranged by 660 $-750 \mathrm{~mm}$ while the VF1 viscosity class is ranged by $6-10$ seconds.

\subsection{STATISTICAL PROGRAM}

Analysis of variance (ANOVA) has been used for examining the significance of the factors considered for developing the strength model and subsequently fitting an empirical model for compressive strength in terms of the significant mixture factors using multiple linear regression. Table 3 shows the statistical terminologies, which they are important conduct and understand the ANOVA as proposed by Ahmad and Alghamdi, (2014).

\section{RESULTS}

The optimal reference mixture with target compressive strength reaching $75 \mathrm{MPa}$ and (SF2 and VF1) as a targeted classification for the fresh properties had the following spec-

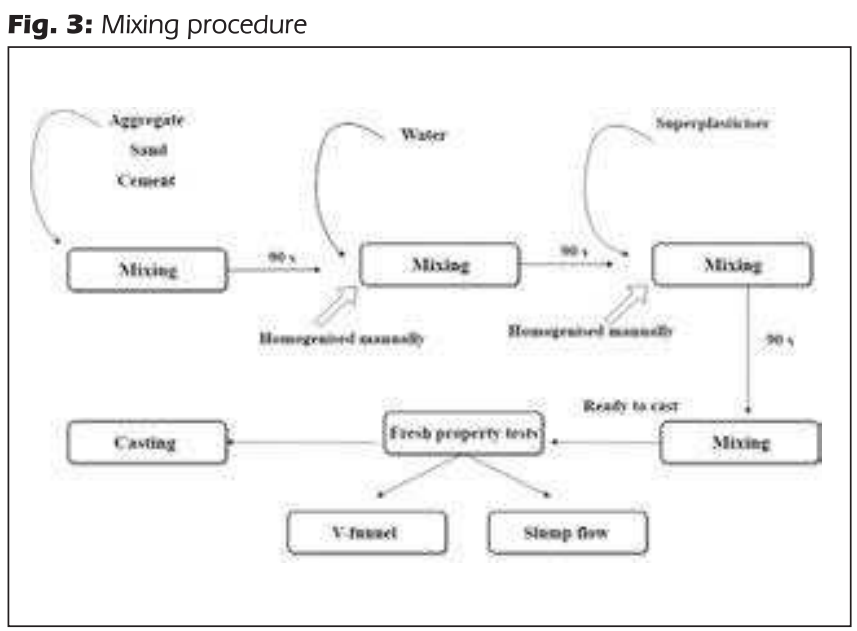


Table 3: Description of the statistical terminologies used in ANOVA.

\begin{tabular}{|c|l|}
\hline Statistical terminology & \multicolumn{1}{c|}{ Description } \\
\hline $\begin{array}{c}\text { Degree of Freedom (df) } \\
\text { Sum of Squares } \\
\text { (SS) }\end{array}$ & $\begin{array}{l}\text { It is the number of values in the final calculation of a statistic that are free to vary. } \\
d f=n-1, \text { where } n \text { represents the number of groups. }\end{array}$ \\
\hline $\begin{array}{c}\text { Mean Square } \\
\text { (MS) }\end{array}$ & It is the squared distance between each data point (Xi) and the sample mean (M), summed for all $n$ data points. \\
\hline F-Ratio & $\begin{array}{l}\text { It is ratio of MS of the concerned factor to the MS of the error. A higher F-Ratio indicates a significant effect } \\
\text { of the factor. }\end{array}$ \\
\hline $\boldsymbol{P}$-Value & $\begin{array}{l}\text { It is a measure of acceptance or rejection of a statistical significance of a factor based on a standard that no } \\
\text { more than } 5 \%(0.05 \text { level) of the difference is due to chance or sampling error. In other words, if the P-value for } \\
\text { a factor is } 0.05 \text { or more, it would not have effect on the dependent variable. }\end{array}$ \\
\hline
\end{tabular}

ifications: $500 \mathrm{~kg} / \mathrm{m}^{3}$ cement content, $45 \%$ for $0 / 4 \mathrm{~mm}$ aggregate fraction, $55 \%$ for $4 / 16 \mathrm{~mm}$ aggregate fraction and $0.35 \mathrm{w} / \mathrm{c}$ ratio. It is M1 mixture in Table 4, which shows the average 28-day compressive experimentally (Sc) for all the eight concrete mixtures along with the minimum dosage of the needed HRWRA to achieve the targeted classification for the fresh properties. The data given in Table 2 and Sc values given in Table 4 has been utilized for statistical analysis to examine the significance of the mixture factors and subsequently to obtain a multiple linear regression model for compressive strength in terms of the factors considered.

Table 4: Compressive strength test results based on experiments and Eq. (1)

\begin{tabular}{|c|c|c|c|}
\hline $\begin{array}{c}\text { Mixture } \\
\text { name }\end{array}$ & $\begin{array}{l}\text { compressive } \\
\text { strength based on } \\
\text { experiments } \\
\text { (Sc) } M P a\end{array}$ & $\begin{array}{c}\text { HRWRA } \\
\text { dosage } \\
\mathrm{kg} / \mathrm{m}^{3}\end{array}$ & $\begin{array}{l}\text { compressive } \\
\text { strength based } \\
\text { on Eq. (1) } \\
\text { (Sc') } \mathrm{MPa}\end{array}$ \\
\hline M1 & 81.98 & 1.5 & 81.23 \\
\hline M2 & 79.29 & 2 & 78.13 \\
\hline M3 & 73.27 & 2 & 73.49 \\
\hline M4 & 75.04 & 1.5 & 76.59 \\
\hline M5 & 77.36 & 1.75 & 77.98 \\
\hline M6 & 73.73 & 2.25 & 74.88 \\
\hline$M 7$ & 70.59 & 2.25 & 70.24 \\
\hline M8 & 74.92 & 1.75 & 73.34 \\
\hline
\end{tabular}

Based on the ANOVA test results which done with the Microsoft Excel solver 2013 by utilizing the experimental program results; the multiple linear regression model for the compressive strength has been obtained $\left(\mathrm{R}^{2}=0.903\right)$ :

$S c^{\prime}=114.019-21.656(F / T)-154.425(w / c)+0.062(C c)$

Where is the 28-day compressive strength in MPa based on Eq. (1), $\mathrm{Cc}$ is the cement content in $\mathrm{kg} / \mathrm{m}^{3}, \mathrm{w} / \mathrm{c}$ is the water to cement ratio by mass, and $\mathrm{F} / \mathrm{T}$ is the fine to total aggregate ratio by mass. However, the proposed model in Eq. (1) is limited to the range values of the proposed variables.

The results of ANOVA for the compressive strength model are presented in Table 5, which shows that the three factors have a significant effect on the compressive strength and workability performance of SCHPC due to the low PValue (less than 0.05). Thus all the proposed factors have to be considered to achieve the maximum possible compressive strength of SCHPC by taking into considerations the minimum required HRWRA dosage. SCHPC proved its sensitiv- ity to the ingredient proportions and mixing procedure, which is much more than other types of concrete.

Table 4 also shows the results of compressive strength based on the proposed model in Eq. (1). In addition, it refers to the optimal reference SCHPC mixture, which complies with the experimental results but with more confidence with its optimal combination. The value of statistical optimization could be clearer in case of more complicated model or in case of a higher number of variables and levels.

\section{CONCLUSION}

Optimal mix design of self-compacting high-performance concrete (SCHPC) is assessed based on the basic material aspects of SCHPC, namely, aggregate fraction distribution, w/c ratio, and cement content, in addition to the mixing procedure. Thus, all the proposed factors have to be considered to achieve the maximum possible compressive strength by taking into considerations the minimum required high range water reducer admixture dosage. SCHPC proved its sensitivity to the ingredient proportions and mixing procedure, which is much more than other types of concrete. Where the proposed factors had a significant effect on the compressive strength and workability performance of SCHPC. As well as the main issues of SCHPC have been introduced with suggestions for a sustainable SCHPC through using rrecycled concrete aggregate as a partial replacement of natural aggregate and unpossessed waste powder materials as cement replacing materials, in addition to optimising the minimum required dosage of HRWRA.

\section{REFERENCES}

ACI CT-13 (2013): “ACI Concrete Terminology”, ACI Standard; p. 74.

BS EN 197-1:2011. "Cement Part 1: Composition, specifications and conformity for common cements", British Standards Institution.

BS EN 1008:2002, "Mixing water for concrete-Specification for sampling, testing and assessing the suitability of water, including water recovered from processes in the concrete industry, as mixing water for concrete", British Standards Institution.

BS EN 12620:2002+A1:2008, “Aggregates for concrete', British Standards Institution.

Ahmad, S. \& Alghamdi, S. A. (2014), "A Statistical Approach to Optimizing Concrete Mixture Design. The Scientific World Journal"; p. 7, https://doi. org/10.1155/2014/561539.

Ajdukiewicz, A. \& Kliszczewicz, A. (2002), "Influence of recycled aggregates on mechanical properties of HS/HPC", Cement and Concrete Research, 24(2), pp. 269-279, https://doi.org/10.1016/S0958-9465(01)00012-9.

Bui, V. K., Montgomery, D., Hinczak, I. \& Turner, K. (2002), "Rapid testing method for segregation resistance of self-compacting concrete". Cement and Concrete Research, 32(9), pp. 1489-1496, https://doi.org/10.1016/ S0008-8846(02)00811-6.

Cameron, I. (2003), "Self-compacting concrete: a versatile material". Concrete Structures, 37(2), pp. 16-18. 


\begin{tabular}{|c|c|c|c|c|c|c|}
\hline & $d f$ & $S S$ & $M S$ & $F$ & \multicolumn{2}{|c|}{ Significance F } \\
\hline Regression & 3 & 83.297 & 27.766 & 12.785 & \multicolumn{2}{|c|}{0.016} \\
\hline Residual & 4 & 8.687 & 2.172 & - & \multicolumn{2}{|c|}{-} \\
\hline Total & 7 & 91.984 & - & - & \multicolumn{2}{|c|}{-} \\
\hline Source & Coefficients & Standard Error & P-value & Lower 95\% & Upper 95\% & Significance \\
\hline Intercept & 114.019 & 16.502 & 0.002 & 68.202 & 159.837 & - \\
\hline$(F / T) \%$ & -21.656 & 6.947 & 0.036 & -40.944 & -2.368 & yes \\
\hline$(w / c) \%$ & -154.425 & 34.736 & 0.011 & -250.867 & -57.984 & yes \\
\hline (Cc) $\mathrm{kg} / \mathrm{m}^{3}$ & 0.062 & 0.021 & 0.041 & 0.004 & 0.120 & yes \\
\hline
\end{tabular}

Collepardi, M., And Massidda, L. (1976), "The influence of water-reducing admixtures on the cement paste and concrete properties. Proceedings of a Conference on Hydraulic Cement Pastes: Their Structure and Properties", Slough, UK: Cement and Concrete Association.

EFNARC 2002, "Specifications and guidlines for self-compacting concrete", English ed.: European federation for specialist cinstruction chemicals \&concrete systems

EFNARC 2005, "Specifications and guidlines for self-compacting concrete", English ed. European federation for specialist cinstruction chemicals \&concrete systems.

Geiker, M., Brandl, M., Thrane, L. \& Nielsen, L. (2002), “On the Effect of Coarse Aggregate Fraction and Shape on the Rheological Properties of Self-Compacting Concrete", Cement, Concrete and Aggregates, 24(1), pp. 3-6, https://doi.org/10.1520/CCA10484J.

Ghanbari, A. (2011), "Self-Compacting High and Ultra High Performance Concretes", $\mathrm{PhD}$ thesis, Cardiff University.

Hassan, K. E., Cabrera, J. G. \& Maliehe, R. S. (2000), "The effect of mineral admixtures on the properties of high-performance concrete", Cement and Concrete Composites, 22(4), pp. 267-271, https://doi.org/10.1016/ S0958-9465(00)00031-7.

Hooton, R. D. (2000) "Canadian use of ground granulated blast-furnace slag as a supplementary cementing material for enhanced performance of concrete". Canadian Journal of Civil Engineering, 27(4), pp. 754-760, https://doi.org/10.1139/100-014.

Hover, K. C. (1998), "Concrete mixture proportioning with water-reducing admixtures to enhance durability: A quantitative model", Cement and Concrete Composites, 20(2), pp. 113-119, https://doi.org/10.1016/S09589465(98)00002-X.

Khatri, R. P., Sirivivatnanon, V. \& Gross, W. (1995), "Effect of different supplementary cementitious materials on mechanical properties of high performance concrete", Cement and Concrete Research, 25(1), pp. 209220, https://doi.org/10.1016/0008-8846(94)00128-L.

Khayat, K. (2000), "Optimization and performance of air-entrained, selfconsolidating concrete" ACI Structural Journal, 97(5), pp. 526-535.

Khayat, K. H. (1999), "Workability, testing, and performance of self-consolidating concrete", ACI Materials Journal, 96(3), pp. 346-353.

Kosmatka, S. H. (2002), "Design and control of concrete mixtures, Ottawa", Cement Association of Canada, book, Cement Association of Canada .

Kwan, A. K. (2000), "Use of condensed silica fume for making highstrength, self-consolidating concrete", Canadian Journal of Civil Engineering, 27(4), pp. 620-627, https://doi.org/10.1139/199-091.

Long, G., Gao, Y. \& Xie, Y. (2015), "Designing more sustainable and greener self-compacting concrete". Construction and Building Materials, 84, pp. 301-306, https://doi.org/10.1016/j.conbuildmat.2015.02.072.
Mueller, H. S., Haist, M., Moffatt, J. S. \& Vogel, M. (2017), "Design, Material Properties and Structural Performance of Sustainable Concrete". Procedia Engineering, 171, pp. 22-32, https://doi.org/10.1016/j.proeng.2017.01.306.

Neville, A. M. (2009), "Properties of concrete", book, Harlow, England; New York, Prentice Hall/Pearson Education.

Okamura, H., And Ozawa, K. (1995), "Mix design for self-compacting concrete", Concrete Library of JSCE, 25, pp. 107-120.

Okamura, H. \& Ouchi, M. (2003), "Self-Compacting Concrete. Journal of Advanced Concrete Technology", 1(1), pp. 5-15, https://doi.org/10.3151/ jact.1.5.

Persson, B. (2001), “A comparison between mechanical properties of selfcompacting concrete and the corresponding properties of normal concrete", Cement and Concrete Research, 31(2), pp. 193-198, https://doi. org/10.1016/S0008-8846(00)00497-X.

Safiuddin, M. (2008), "Development of Self-Consolidating High Performance Concrete Incorporating Rice Husk Ash", $\mathrm{PhD}$ thesis, University of Waterloo.

Suhendro, B. (2014), "Toward Green Concrete for Better Sustainable Environment. Procedia Engineering", 95, pp. 305-320, https://doi. org/10.1016/j.proeng.2014.12.190.

Tasi, C., Li, L. \& Hwang, C. (2006), "The Effect of Aggregate Gradation on Engineering Properties of High Performance Concrete", Journal of ASTM International, 3(3), pp. 1-12, https://doi.org/10.1520/JAI13410.

Taylor, M. R., Lydon, F. D. \& Barr, B. I. G. (1996), "Mix proportions for high strength concrete. Construction and Building Materials", 10(6), pp. 445-450, https://doi.org/10.1016/0950-0618(96)00012-8.

Xie, Y., Liu, B., Yin, J. \& Zhou, S. (2002), "Optimum mix parameters of high-strength self-compacting concrete with ultrapulverized fly ash", $\mathrm{Ce}$ ment and Concrete Research, 32(3), 477-480, https://doi.org/10.1016/ S0008-8846(01)00708-6.

Yen, T., Tang, C.-W., Chang, C.-S. \& Chen, K.-H. (1999), "Flow behaviour of high strength high-performance concrete", Cement and Concrete Composites, 21(5), 413-424, https://doi.org/10.1016/S0958-9465(99)00026-8.

Mohammed Abed (1991) civil engineer (MSc). PhD researcher at the Department of Construction Materials and Technologies, Budapest University of Technology and Economics. Main fields of interests: Green, High-performance, Self-compacting and Recycled concrete. Waste materials, Recycled aggregate and Supplementary cementations materials. Non-destructive testing of concrete, Durability measurements, Fire resistance and Sustainable environment. Email: abed.mohammed@epito.bme.hu. Member of the Hungarian Group of fib and Member of Young Member Group of fib (YMG). 